\title{
On the Nonrelativistic Limit of Action-at-a-Distance Relativistic
}

\section{Classical Mechanics.}

J. G. WraY

Moorhead State College - Moorhead, Minn.

(Nuovo Cimento, $12 \mathrm{~B}, 231$ (1972))

Through an unfortunate oversight the following Figure was missed out in printing the paper.

Fig. 1.

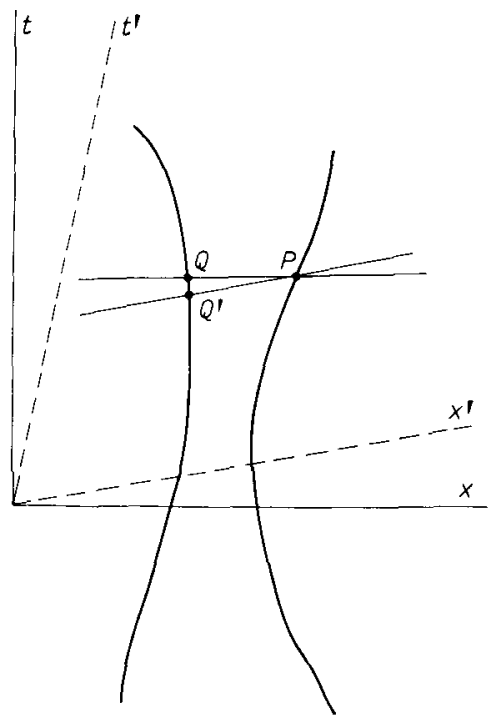

